\title{
Don Winslow, autor de un clásico y otras obras dentro de la narconarrativa mexicano-estadounidense (una guía para forasteros)'
}

\author{
Don Winslow, Author of a Classic Work and Other Works from the \\ Mexican and North- American (USA) Narco Realism
}

\author{
ARTURO E. GARCÍA NIÑO \\ Universidad Veracruzana \\ México \\ eldel54@hotmail.com
}

(Recibido 27-IO-2OI4; aceptado $\mathrm{O} 4-\mathrm{II}-2 \mathrm{OI} 5)$

Resumen. Anclado en lo que se ha dado en llamar la narconarrativa, una expresión literaria binacional fronteriza compartida por México y Estados Unidos, se encuentra Don Winslow, quien con su novela El poder del perro catapultó y cimentó el enunciado subgénero literario para, de ahí, generar otras novelas que tienen al crimen organizado, $y$ sus relaciones con el mundo empresarial y político, como protagonista y tópico, así como a la frontera como espacio donde se desarrollan los hechos narrados. Y sobre la narconarrativa, sobre el autor enunciado, su obra y el contexto binacional versa el análisis aquí incluido

Palabras clave: Don Winslow; narconarrativa; narrativa fronteriza; México-Estados Unidos; crimen organizado.
Abstract. Anchored in what has been called the Narco Realism or Narconarrative, a border binational literary expression shared by both Mexico and the United States, we find Don Winslow, an author that thanks to his novel El poder del perro - The dog's power-, has been catapulted and that has settled down the aforementioned literary subgenre. From that standpoint, other novels that narrate the expression of organized crime, and its relations to the world of business and politics have widely spread. They account for a typical setting where the border is the natural space for the action and the narrated facts. This analysis deals with Narco Realism or Narconarrative, their output and the two-nations context that frames it.

Keywords: Don Winslow; narconarrativa; narrative border; Mexico-United States; organized crime.

\footnotetext{
${ }^{\text {I }}$ Para citar este artículo: García Niño, Arturo E. (2OI5). Don Winslow, autor de un clásico y otras obras dentro de la narconarrativa mexicano-estadounidense (una guía para forasteros). Alabe 12. [www.revistaalabe.com]

DOI: IO.I5645/Alabe.2OI5.I2.4
} 


\section{A la Unión americana \\ la droga entra fácilmente \\ es el país de confianza \\ allá seguro se vende. \\ Los Tucanes de Tijuana}

Se habla del problema mexicano de la droga, pero es un error: ese problema se originó en Estados Unidos. Tenemos el mal hábito de señalar a los mexicanos, colombianos y afganos por producir droga, pero ¿quién la compra?: Cómo se puede decir "quiero comprar esto" y luego culpar al vendedor?

Don Winslow

¿Qué pueden tener en común un ex agente de la CIA, especialista en contrainsurgencia y sólido pilar de la Operación Fénix en Vietnam, quien en 1975, al firmarse el armisticio, se integra a la DEA para ser <asesor> de la Operación Cóndor en México, y una mujer liberal e hija de un político demócrata estadounidense? A botepronto menos que poco o... que cero. Y más acá de que Art(hur) Keller, el policía de marras criado en Barrio Logan de San Diego e hijo de una culiacanense, y Althea, la mujer de éste, sean un buen matrimonio que para bien y para mal vive inmerso durante treinta años en los tiempos cuando el narcotráfico asciende en este México nuestro, y cuando su uso por parte de los políticos mexicanos y estadounidenses genera la llamada narcopolítica² ${ }^{2}$, son ambos personajes de una galería de arquetipos -el viejo y avejentado capo Pedro Avilés, el policía corrupto Miguel “El Tío” Barrera y sus sobrinos Adrián y Raúl, el gringo de origen irlandés Billy Boy Callan y sus compinches, la prostituta de lujo Nora Hayden, el cura Juan Parada, el soplón "Mamada"...- construida por Don Winslow en El poder del perro (2009) -utilizo como referencia los años de publicación en español de las obras de Winslow-, incluida en la excelente y ya de culto colección Roja \& Negra dirigida por el escritor argentino Rodrigo Fresán -autor de Historia argentina (199I); Esperanto (1995); Mantra

\footnotetext{
2 Para un seguimiento de la historia de las drogas y el narcotráfico en México, así como de la narcopolítica, es imprescindible Astorga (i996; 2003); pueden verse también Carey (2OO9), Cedillo (2OII), Hernández (2OIO), Osorno (2009), Valle (I995); y para lo referente a la narcocultura puede verse Astorga (I995; I997), Enciso (2OO4), Ramírez Pimienta (2004; 2OIO), Valenzuela (2002).
} 
(200I); Jardines de Kesington (2004); El fondo del cielo (2009); entre otras obras- para Grijalbo/Mondadori.

Utilizando como matriz de entrada El poder del perro, el presente artículo establece los principios y circunstancias del subgénero literario que hemos dado en llamar narconarrativa, hace un recorrido descriptivo/analítico por/de la obra de Winslow e inserta, como definidoras del subgénero enunciado, a tres de sus novelas; y a dos más las ubica en los linderos de la tal narconarrativa.

\section{La narconarrativa: una definición suprarotular y en tres balazos}

El antecedente más lejano de la narconarrativa vendría a ser la clásica Cosecha roja (I97I), de Dashiell Hammett, publicada de manera integral en I929 bajo este título y que fue dada a conocer a los lectores de Black Mask mediante cuatro entregas entre noviembre de 1927 y febrero de I928. Y la primera obra pretendidamente de ficción, más bien a caballo entre la novela, la biografía y las memorias, documentada dentro del subgénero en México es Diario de un narcotraficante (I967), muy mal escrita por a. [sic.] Nacaveva, publicada en Costa-Amic y ambientada en Culiacán, Sinaloa, principalmente. La misma editorial la reeditaría en 2000 con el nombre completo del autor, que es Ángelo; es también la primera en este subgénero en toda América Latina, por lo menos. Años después, en r993, el italiano Pino Cacucci publicó San Isidro Fútbol, una novela breve en tono de gran guigno, donde lo central es el mundo del fútbol llanero y la corrupción y el narcotráfico son presencias veladas en el trasfondo. Y de ese mismo año es Hielo negro (I993), de Michael Conellly, la segunda entrega de la saga del detective Harry Bosch, donde a partir de las muertes de un agente policial encubierto y un ciudadano latino asesinado se llega al tráfico de una nueva droga -producida por un cártel mexicano del narcotráfico- cuyo nombre da título a la novela.

Con ello como antecedentes se considera para efectos del presente trabajo a la narconarrativa como una expresión literaria realista devenida en subgénero de la novela negra, resultante de la atención acuciosa a una situación binacional -México y Estados Unidos- donde la espiral de violencia creciente y presente en el día a día -generada por la incidencia del crimen organizado en la vida cotidiana durante por lo menos los más recientes treinta años y producto de la corrupción política, empresarial y ciudadana-, hace muy difícil no poner atención a ella y a las situaciones que genera -que pueden transitar de la tragedia a la tragicomedia con escalas en el melodrama o la comedia a secas-. De igual manera ha integrado a su caudal lingüístico las nomenclaturas -de los nombres reales a los apodos-, las expresiones verbales de nuevo cuño o con nuevos significados "-halcones", "dar piso", "la letra", "los de la letra", "la maña", "los viejones", "poner el dedo"- y las mitologías y supersticiones -Malverde, la santa muerte o la niña o la flaquita.”

En lo general, el subgénero incluye textos que asumen el tópico como elemento vertebrador, lo rozan fronterizamente o lo utilizan como trasfondo, y que van de Un asesi- 
no solitario (1999), El amante de Janis Joplin (2002), Efecto tequila (2004), Balas de plata (2008), La prueba del ácido (2OII) y Nombre de perro (2OI2) -todas escritas por Elmer Mendoza-, a Trabajos del reino (Herrera, 2004), La conspiración de la fortuna (Aguilar Camín, 2005), Al otro lado (Yépez, 2008), Malasuerte en Tijuana (Peña, 2009), Corazón de Kaláshnikov (Páez Varela, 2009), Fiesta en la madriguera (Villalobos, 2Iо), Perra brava (Alarcón, 2OIO). Pero dado que el fenómeno del narcotráfico, y del crimen organizado en sentido ampliado, es compartido de manera binacional entre nuestro país y Estados Unidos -iy por supuesto que es cuasi inherente a la economía mundo en que se asienta la globalidad!-, a que los carteles productores y distribuidores de drogas tienen su asiento en la franja fronteriza compartida por estas dos naciones, y a que los estados a cada lado de la franja han conformado un escenario - ¿una región literaria?- compartido patrimonialmente por escritores de ambos lados, debemos agregar a los autores y obras enunciados La reina del sur (Pérez-Reverte, 2002) ${ }^{3}$.

\section{Don Winslow y Elpoder del perro}

Publicada originalmente en Estados Unidos en 2005, y escrita durante seis años, Elpoder del perro es la magna novela de la narconarrativa -sin ser la mejor del subgénero, que conste- ${ }^{4}$. Contada en tono de western noir es también la primera obra traducida al español de este newyorquino de 57 años que ha sido actor, encargado de una sala de cine, detective privado y autor de la saga del detective Neal Carey -integrada por $A$ cool breeze on the underground, nominada al Premio Edgard Alan Poe; While Drowning in the Desert; A long walk up the waterslid; Way Down on the High Lonely; The Trail to Buddha's Mirror-, así como de El invierno de Frankie Machine (20IIa), cuyos derechos de filmación fueron comprados por Robert de Niro para ser filmada por Martin Scorsese y que parece terminará dirigiendo Michael Mann; de Muerte y vida de Bobby Z (2OIrb) -incluida también en la colección Roja \& Negra-, llevada al cine en 2007 por John Herzfeld; de Salvajes (2OIIc), llevada al cine con guion y dirección de Oliver Stone, y de la precuela de ésta: Los reyes de lo cool (2OI2a); de un remake del clásico de espías en tiempos de la guerra fría: Shibumi (2OI2b), firmada por Trevanian, bajo el título de Satori (เ979); de El club del amanecer (2009b) y su secuela La hora de los caballeros (20I2c).

Como sea, es El poder del perro la que puede considerarse obra cumbre de su autor, sin duda alguna, pero también la hasta ahora novela más importante y acabada -sin ser la mejor, que vuelva a constar- acerca del narcotráfico en/entre México y Estados Unidos. Es asimismo una galería del terror donde a lo largo de más de setecientas páginas se transparentan los rostros de Ernesto Fonseca, de Enrique Camarena, de Amado Carrillo,

\footnotetext{
3 Para los detalles y profundización acerca del subgénero puede verse García Niño (2OI3).

${ }^{4}$ Ese lugar le corresponde a Entre perros (Almazán, 2009), cuyo autor escribió también El más buscado (2OI2), novela que incluye como personaje central al narcotraficante precisamente más buscado en ambos lados del Río Bravo hasta su captura hace unos meses, después de haberse fugado de un penal de alta seguridad en 2oor: Joaquín "El Chapo" Guzmán, mismo que aparece en esta obra como Felizardo "El Chalo" Gaitán.
} 
de los hermanos Arellano Félix, del general Rebollo, del cardenal Posadas, del mafioso irlandés Mickey Fetherstone y su par italiano Paul Castellano, de Luis Donaldo Colosio, del coronel Oliver North y el affaire Irán-Contras... entre muchos.

Winslow construye con Elpoder del perro una crónica a muchas voces que arranca en r997 en el pueblo de El Sauzal, Baja California, para de ahí, mediante flashback, ir a Badiraguato, Sinaloa, en I975 y en plena Operación Cóndor, iniciando así un recorrido histórico que abarca hasta 2004 en "algún lugar" del mundo. Es, pues, un lapso de casi treinta años durante los cuales el crimen organizado, la política nacional mexicana y gringa, la geopolítica internacional y el mundo trasnacional empresarial se imbrican entre sí, y donde los únicos personajes que trascienden a las tres décadas contadas son las mafias irlandesa e italiana newyorkinas, la mexicana y Fidel Castro.

Los personajes históricos y los de ficción caminan tomados de la mano en esta obra que transita por lo que James Ellroy ha dado en llamar con certeza <la historia alternativa>, cuyas muestras ejemplares son su "Cuarteto de Los Ángeles" -integrado por La dalia negra (1993), Jazz Blanco (2005a), El gran desierto(2005b) у L.A. confidencial (1993)- y su tríptico "Tabloide Estadounidense" -compuesto por América (2001a), Seis de los grandes (200Ib) y Sangre vagabunda (20IO)-5, así como la disección histórica hecha por Gore Vidal al través de Burr (1975), I876 (1977), Washington DC (1994a), Hollywood (I994b) y apostillada con La edad de oro (2002). Con la obra de estos tres autores -Ellroy, Vidal y Winslow-, puede edificarse una versión muy precisa y alternativa a la historia y a la historiografía oficiales, que arranca en los inicios de Estados Unidos como nación y los claroscuros de los padres fundadores para culminar, hasta ahora, en la primera mitad de la década inicial del siglo XXI, y para el caso mexicano de 1975 al $2004^{6}$.

"Un día me levanté y vi en el periódico que ig inocentes habían sido asesinados en un pequeño pueblo mexicano [en el estado de Baja california] al que solíamos ir a pasar un fin de semana barato... me preguntaba insistentemente, ¿¿cómo ha podido pasar eso?'... y fui incapaz de encontrar alguna respuesta... Supongo que cuando [esto pasa] la siguiente opción es escribirla” (Salerno, 20Io), afirma Don Winslow. Y así inicia la novela: con la muerte de esa familia en un pueblo del citado estado mexicano fronterizo como piedra de toque de una narración plagada de violencia, sangre y sesiones de tortura, que lindan con lo enfermizo y establecen una subcultura amalgamada por la patología colectiva encarnada en ambas partes: policías y militares, por un lado, y los delincuentes por el otro?. Estilo e imaginación devienen aquí aportes centrales de esta obra acerca de

\footnotetext{
5 Para un análisis de la obra de Ellroy, así como de Barry Gifford y Elmore Leonard, puede verse García Niño (2OO2). Ellroy publicó recientemente Perfidia (20I5), novela con la cual viaja a diciembre de I94I y que es la primera entrega de otro cuarteto, previo al de Los Angeles, que concluirá justo antes de La dalia negra; y en la cual retoma varios personajes actuantes en el Cuarteto y en la trilogía Tabloide Estadounidense.

${ }^{6} \mathrm{El}$ antecedente literario inmediato a la obra de Winslow, en el sentido de tener como eje el crimen organizado trasfronterizo México-Estados Unidos, sería el Barry Gifford de Perdita Durango (1992) y, sobre todo, el de El asunto de Sinaloa (1999).

7 Diego Enrique Osorno, en su imprescindible reportaje La guerra de los zetas. Viaje por la frontera de la necropolítica (2OI2), utiliza el concepto de "máquinas de guerra", acuñado por Achille Mbembe (2OII), para referirse a $<$ eso $>$ en que se han convertido tanto el crimen organizado como las fuerzas militares y policíacas en México .
} 
un tópico que se desparrama en la cotidianidad y se inserta en sus resquicios, para incidir y definir historias de vida: los jóvenes que inician carrera delictiva $<$ fayuqueando $>$ blue jeans para terminar siendo grandes capos del narcotráfico internacional, por ejemplo.

Habitante de la costa oeste en la franja fronteriza mexicano-estadounidense, Winslow afirma que vivir en ese espacio binacional puede conducir a dos opciones: a olvidarse de todo y dedicarse a surfear, o bien a cuestionarse el estado de cosas existente en el entorno e ir en pos de respuestas a actos plagados de crueldad, manifestados en ejecuciones como aquella en Baja California de la que daba cuenta el diario. Por ello decidió acometer El Poder del Perro, porque, dice, empezó "a pensar que quizás fuese responsable de no haber escrito antes de esto y que debía pagar [como fronterizo] un alquiler... en forma de libro.” (Morán, 2OIO). Y teniendo en cuenta los antecedentes y condiciones históricas y coyunturales enunciados líneas atrás, los cuales definen y en los cuales se inscribe la práctica narrativa de Wisnlow, y a su novela cimera como espejo y detonante, pasaremos revista a su obra en las páginas venideras.

\section{Salvajes}

Puesto ya en el camino con Elpoder del perro, Winslow continuó forjando lo que hemos dado en llamar la narconarrativa con la novela Salvajes, donde una vez más el tránsito de la droga entre los dos países que comparten la frontera más porosa, más grande y más circulada del mundo, va generando un conjunto de circunstancias que rebasan, como en toda acción social, las voluntades de los actores. Vemos así transcurrir las vidas de Ophelia, o simplemente $\mathrm{O}$, la de los orgasmos escandalosos y en eterno conflicto con Rupa, su madre; la de Ben, hijo y nieto de izquierdistas -cuyos padres son siquiatras < progres> y ex hippies en la California dorada-, pacifista y políticamente correcto, preocupado por hacer el bien y creador de organizaciones no gubernamentales en pro de los jodidos del tercer mundo, quien estudió en Berkeley botánica y marketing; y la de Chon -llamado realmente John-, excombatiente en la guerra del golfo, fuerza de elite y SEAL. Los veinteañeros Ben y Chon son excelentes voleibolistas playeros, motivo por el cual se conocieron luego de que Chon regresara de Afganistán y Pakistán - Istanlandia lo llama éste de manera genérica.

Trío entre tríos, los protagonistas centrales de Salvajes se mueven para hacer y compartir todo. Ben y Chon tratan de cuidar que O no se manche con lo que ellos hacen, que es producir la mejor marihuana hidropónica, dicen, "del mundo", manejada en términos de comercio justo, orgánica mezcla de sativa e índica que da en el justo medio: ni aplatana ni pone loco al personal, esgrimen. Tienen el mejor negocio de la costa de California desde su centro de operaciones en Laguna Beach y al través de un conjunto de vendedores al menudeo con buenos salarios y justo trato. Por esto, y por sus capacidades para establecer una red de protección en torno a su comercio justo, son respetados y tienen a sus geeks que mueven el dinero al través de las redes digitales; y tienen, por supuesto, a su hombre de finanzas. 
Son felices los tres porque viven bien, hasta que los mexicanos del Cártel de Baja se da cuenta que su negocio en Estados Unidos no crece por la competencia de los amigos Ben y Chon. Decide entonces el Cártel que los dos estadounidenses les vendan a ellos al mayoreo durante tres años, luego de los cuales, les proponen, los dejarán en libertad de seguir haciendo lo que quieran hacer. La irrupción del azar, sustento de la vida y de la historia, coloca al par de amigos en las situaciones límite ante las cuales deben dar respuestas para salvarse.

Vemos entonces que en California algunos mexicanos tienen dos caras: una que representa el esfuerzo diario para lograr una mejor vida como jardinero esforzado, y otra que es ser el hombre del Cártel de Baja en territorio estadounidense. Esto es Miguel Arroyo, alias "El Lado" o simplemente Lado -por helado, porque sus ojos son fríos como la piedra-. Ex policía de Baja California, ex integrante de "Los Zetas", de 46 años, Arroyo tiene dos hijos pequeños que son buenos jugadores de beisbol y una hija, además de ser el más leal hombre de confianza de la capo del Cártel: Elena Lauter.

Madre de dos hijas y un hijo -Magda, la menor, estudia antropología en la Universidad de Berkeley; Claudia es la de en medio y Germán, ingeniero, el mayor-, Elena asumió el mando del Cártel de Baja al ser capturados y/o muertos sus hermanos -uno preso en San Diego, otro en México y dos asesinados- y su marido -Filipo Sánchez, guapo y mujeriego <asesinado a lo pendejo >, como dice ella-. Y decidió encabezar al cártel para evitar que lo tuviera que hacer su hijo, quien, según su madre, "no servía para eso [porque] heredó la falta de carácter e inteligencia de su padre” (Winslow, 2OIIc: I22), debilidades que este último compensaba con ser muy buen amante; lo que condujo a que Elena se fuera con él a los ig años nomás porque quería salirse de su casa, estar fuera del control de sus hermanos y... pues para gozar con el buen amante.

Elena está aliada con "Los Zetas" y enfrentada a "El Azul”, quien se ha unido al Cartel de Sinaloa -el más poderoso- después de que los hermanos Lauter fueron cayendo y por el machismo que impidió a los aliados y operadores de sus hermanos aceptarla a ella. "Lo malo... es que no era lo que ella quería. Sin embargo, como era la única Lauter que quedaba en pie, era su obligación: le tocaba... [Y ahora anda ocupada el día de los fieles difuntos] porque tiene que llevar presentes a un montón de sepulturas: un esposo, dos hermanos, cinco sobrinos, innumerables primos, tantos amigos que ha perdido la cuenta."(I2I). Y esta mujer quiere apoderarse, según O, de la marihuana de Ben y Chon porque los cárteles de la droga "son como Walmart", cuestión en la que Chon está de acuerdo con O: "Pues sí, son como Walmart... y se han movido horizontalmente para ofrecer una amplia variedad de productos: no sólo venden drogas, sino también seres humanos, tanto para el mercado laboral como para el sexual, y últimamente han entrado en el lucrativo negocio de los secuestros". $(27)^{8}$

\footnotetext{
${ }^{8}$ En el documental Narco Cultura (2013), dirigido por Shaul Schwarz, el dueño de una compañía productora de discos compactos y videos que hacen apología del narcotráfico expone que la primera vez que llevó sus productos a Walmart, para que la cadena de tiendas los distribuyera, ésta solo le compro Ioo unidades; unos días después, agotada la mercancía, Walmart le compró 50 mil unidades.
} 
Ante la situación ominosa en que se encuentran, las personalidades y voluntades de Ben y Chon se enfrentan, saliendo a relucir fragmentos de sus historias de vida. Nos enteramos así de que a Chon a los tres años su padre le dijo que saltara de la repisa de la chimenea y que lo atraparía, pero no fue así: lo dejó caer al grito de “¡olé!” y al entonces niño se le clavó un diente en el labio. "No confíes [le dijo su padre]. Nunca. En nadie." (44) Por esto es que Ben dijo en alguna ocasión que "Chon habría sido "criado por lobos', si no fuera porque los lobos son mamíferos de sangre caliente que se ocupan de sus crías.” (45) Porque a Ben le repelen, según él, las malas acciones y la mala entraña de los seres humanos, $\mathrm{y}$ "se esfuerza por ser no violento y honesto en un negocio que es violento y deshonesto" (65) per se. De tal manera que ante la agresión del Cártel de Baja decide abandonar el negocio y dedicarse a las energías alternativas. "Podríamos cambiar este mundo de mierda" [le dice a Chon, pero éste piensa que] Ben todavía no sabe... que uno no puede cambiar el mundo: es el mundo el que te cambia a ti." (83)

Sabe también Chon que el mundo en que están insertos es de salvajes, y que aunque Ben quiera paz, "no puedes hacer las paces con unos salvajes" (84), menos cuando Dennis, agente de la DEA al servicio de Ben y Chon, les recomienda, al enterarse del ultimátum que les puso el Cártel de Baja: “¿Quieren que les dé un consejo, muchachos... y muchacha? Los voy a extrañar y extrañaré su dinero, pero empiecen a correr. Váyanse lejos y enseguida." (93) Consejo que Ben propone tomar en cuenta y echar a correr, pero Chon se niega, porque aprendió en su incursiones en $<$ Istanlandia $>$ que "si dejas que los demás crean que eres débil, más tarde o más temprano vas a tener que matarlos.” (II8) Como hizo Elena al tomar el control del Cártel y "El Guapo” le dijo a Lado: "a mí esa puta ya me puede mamar la verga; Lado le disparó en los genitales y le preguntó: ‘¿Qué verga, cabrón? ¿Ésta?’ (г2I)Y a continuación preguntó si entre los presentes alguien más quería que se la mamaran. Luego se la cortó y se la metió en la boca al ya ex guapo En las siguientes dos semanas aparecerían otros siete cadáveres con la marca del Lado. Mundo de salvajes éste, sí, donde la propia Elena declara, como producto del mismo, ser "la mujer que hace lo que tiene que hacer. Soy la mujer en la que me han convertido" (I26), aquella que, como afirma la vox populi, cuando "tiene el mes, sí que corre sangre." (I26)

En Salvajes, Winslow hace un flashback interdiscursivo y resume, entre las páginas 89 y 93, lo central de la trama y las anécdotas de El poder del perro, para contextualizar el tiempo de canallas en que se desarrollan ambas obras y para dejar en claro que "la guerra entre cárteles pasó la frontera como los mojados. Los 30 contra los 94 y éstos contra aquellos y Baja o Sinaloa o El Azul detrás de ellos. [Y] Ben reclama que él no tiene que ver con ello, que él sólo vende la mejor mota.” (279); lo que es cierto, como lo es el hecho de que desde las playas de California -al ritmo del rock, jugando voleibol, tomando café y cerveza y trepados en un ola- el mundo del dolor, la violencia y las víctimas de esa guerra les es muy lejano a Ben y a Chon, hasta que los golpea Elena y se dan cuenta, como afirma este último, que al fin y al cabo "en realidad uno no siente el dolor ajeno: sólo puede imaginárselo." ( (г76) 
Y entonces sí, Ben y Chon tienen que echar a volar la imaginación para responder al Cártel de Baja en el mismo terreno que $<$ los salvajes mexicanos $>$ del otro lado de la frontera, para descubrir que las diferencias entre aquellos y ellos no son patrimonios étnicos ni nacionales y sí culturales y universales, y que la violencia y el salvajismo están a disposición de quienes se ven inmersos en situaciones límite, que son a fin de cuentas las constantes de la vida misma. "Ben sabe muy bien [porque lo ha descubierto ya] que las fronteras son estados mentales" (302), y bajo tales circunstancias el actuar de él y Chon será cambiante, adaptable a las coyunturas que se van presentando en su enfrentamiento con Elena y su gente, lo que le imprimirá a la novela de Winslow un ritmo vertiginoso, seco y en varios escenarios, donde el tiempo parece detenerse a veces para de pronto arrancar otra vez. Y en ese ir y venir, el humor ácido de los personajes acompañará a los muertos y la sangre manará de esos salvajes por oficio y esos salvajes por opción y con el oficio en gerundio: unos viviendo al sur y los otros al norte del Río Bravo, hermanados por $<$ un estado mental $>$ muy poroso y veleidoso llamado frontera que conjuga, como Orson Welles dice al través de Charlton Heston, el policía corrupto en Sombras del mal, "a lo peor de ambos lados", hecho que Barry Gifford demuestra con cada uno de los personajes de todas sus novelas y que Winslow corrobora con su solvente capacidad narrativa.

\section{El invierno de Frankie Machine}

Quizás para alejarse de la frontera y las drogas vueltas personajes en El poder del perro y en Salvajes, Winslow decidió abordar, en El invierno de Frankie Machine, la aparente vida tranquila de Frank Machiano, un vendedor de carnada para pescar, de pescado para restaurantes y que lava la mantelería de éstos; que es agente inmobiliario, patrocinador de un equipo de beisbol infantil, organizador de torneos de pesca para niños y querido por todos como buen ciudadano modelo. El mismo que paga puntualmente sus impuestos por la experiencia que le dio el caso Capone, porque sabe que en su "país puedes hacer casi de todo, con la condición de que hagas tus aportes al Estado. El Tío Sam quiere su parte y, mientras lo obtenga, puedes hacer casi todo lo que te dé la gana, siempre y cuando no se lo refriegues en las narices." (Winslow, 20Ira: 42) Lo que nadie, o casi nadie, sabe en su ámbito inmediato es que el viejo Frank es un sicario retirado de la mafia de San Diego, conocido tiempo atrás como Frankie Machine.

"Quería decir que la mafia existe en California... [y] empecé a estudiar la historia del crimen organizado en San Diego... muy conectado con la política... me basé en un tipo al que conocí de joven, y lo puse... para... contar la historia del crimen organizado de la ciudad en un periodo de treinta años." (Weinman, 2OIO), dice Winslow, y se dedica en las primeras cincuenta y ocho páginas a definir con maestría el contexto, para dar cuenta de que en pleno invierno californiano a Frank Machiano/Frankie Machine ya le llegó el suyo propio a la edad de 62 años, luego de divorciarse sin haber dejado de estar al tanto de su ex mujer, con la que tuvo una hija, entrañable para él, que va a estudiar medicina, y de 
tener una nueva mujer con la que se la pasa bien. Es también Frank un amante de la ópera y del buen café. Bajo estás condicionantes, como en el mejor Elmore Leonard y en homenaje permanente a Pirandello, el pasado del personaje central se inserta por aparente azar en su idílico presente, y su cotidianidad cambiará de una hora a la otra para dejar que su historia se le venga encima, como producto de la corrupción y las ansias de venganza de aquellos con los cuales vivió tiempo atrás día a día y noche a noche.

Novela crepuscular en tono de flash back/flash front, donde Machine el antihéroe se desempolvará por fuerza de salvar su vida y la de sus cercanos, y novela políticamente incorrecta que deja caer con alevosa dosificación datos que ilustran la relación corrupta entre el poder político y la mafia estadounidenses, y con guiños al James Ellroy de la trilogía American Magazine, El invierno... es también, como toda buena obra crepuscular, una novela nostálgica en torno a un hijo -Frank Machiano- de padre atunero, que ayudó a aquel en la pesca, que creció y ya adolescente contribuyó a la producción y reproducción de una cultura anclada en la costa oeste en la "época [los sesentas] de las tablas [de surf] largas y grandes... la época de sacar los diez dedos por la proa y de ir a la playa con la tabla, y de los estupendos riffs de guitarra de Dick Dale y las canciones de los Beach Boys.” (I8) ${ }^{9}$. En esa época donde, según el propio Frank/Frankie, los muchachos pensaban "que aquellos veranos no acabarían nunca: [y] nunca se [les] ocurrió que alguna vez [sentirían] el frío en los huesos.” ( (9)

El frío sí, inherente al invierno presente cuando Machiano/Machine vuelve a vivir en un mundo de traiciones y venta al mejor postor, donde él se manifiesta como posiblemente único y con un ethos muy particular: el de quien cumple su trabajo y es leal a quien le paga, actuar que parece cuestionar el cuasi aforismo de Frank Baptista -apodado Bap-, su mentor: "Todo el mundo tiene su precio, Frank" (II6). Y sólo es aparente el cuestionamiento porque es precisamente Frankie quien confirma la regla con su lealtad a quien le paga, y por ello es que se mete en el problema donde es perseguido por la mafia y la policía en el contexto de la Operación Aguijón G, llevada a efecto por la FBI en contra de los mafiosos propietarios de los locales de desnudistas en la costa californiana.

A salto de mata por la persecución de la mafia y de la policía, Frankie "La Máquina" de matar, el ex marine que regresó en I968 condecorado de Vietnam, y que fue dado de baja con honores por haber sido un efectivo francotirador, tiene para sí, más acá de lo que motivó las condecoraciones del gobierno de su país, el orgullo de saber que sólo mató soldados vietnamitas, porque tuvo el cuidado de evitar los $<$ daños colaterales $>$-eufemismo con el que se designa a las víctimas inocentes-. "Es curioso... [reflexiona Frank], pero a mí me entrenó el gobierno federal” (II6) -igual que a “Los Zetas” en México, vale agregar-. Asimismo "se da cuenta de que ha matado a más hombres para el Estado que para la mafia" (I53) y hace suya la canción de "The Surfaris", titulada Surfer Joe -uno de sus éxitos nacionales junto al cimero instrumental titulado Wipeout-: "Joe, el surfista, se ha

9 “Dick Dale \&The Del-Tones” fueron pioneros del surf, junto a “TheVentures”, y autores de un clásico: Misirlou, incluida en el soundtrack de Pulp Fiction. 
enrolado hoy en la infantería de Marina del Tío Sam/ Lo destinaron a Pendetlon, que no queda demasiado lejos." (пі6).

Pero Frankie Machine no sólo mató mucha gente para el Estado de manera legal en Vietnam, sino que cuando Richard Nixon -a quien Frankie conoció en I972 porque aquel se reunió para su campaña de reelección con los mafiosos del sindicato del transporte en California- fue apoyado por la mafia de San Diego en su primera elección y "el dinero pasaba por la compañía de taxis en cantidades $<<$ donadas $>>$ por los propietarios y los choferes" (I57), Frank, que es demócrata y manejaba por entonces un taxi, se enteró de lo anterior al ver un cheque de él donado para la campaña del republicano, protestó. Mike Pella le dijo que se relajara, que no era su dinero -sino de la mafia que hacía el depósito a nombre suyo- y le preguntó que si prefería que Bobby Kennedy fuera el presidente y que los metiera a todos en la cárcel. Machine tuvo que reconocer que Pella tenía razón y que una vez más él estaba haciendo trabajos sucios -unos legales y otros no- para el stablishment político, lo que no le impidió por lo menos lamentarse, echando por delante su talante liberal como un simple ciudadano: "Así son las cosas. A Bobby [Kennedy] le pegan dos tiros en la cabeza y a Nixon le envían cheques." (I66) La mafia de cuello blanco y los políticos no se ensuciaban las manos porque para eso estaban los Frankie’s. “¿Cuántas personas tienen que morir [se pregunta éste] para que la gente guapa siga siendo guapa?" (238) Y la respuesta es elemental: los necesarios en tanto puedan seguir pagando a gente como Frankie Machine, "un asesino a sueldo de primera” (395), según lo define su amigo surfista y policía Dave Hansen.

Sin embargo, Frank/Frankie es un resistente que pone la amistad, construida en las afinidades y emociones compartidas -como el haber $<$ montado $>$ en la cresta de olas extraordinarias y por ende únicas-, por encima de muchas prioridades y por encima del tan cacareado estado de derecho -al igual que lo hace Dave Hansen-, pero no duda en poner la justicia a secas por encima de todo, e incluso conceder la gracia del perdón a contrapaso de su máxima: ser leal a quien le paga. Ejemplo de ello es lo que asienta cuando tuvo que seguir a un hombre en México a lo largo de Baja California, el noroeste, el noreste, el sureste, el Caribe mexicanos y el Distrito Federal, capital del país: "lo que debería haber hecho [el perseguido] desde el principio [era] irse a una población pequeña, donde podría haber comprado la protección del comandante local. Nosotros le habríamos ofrecido más, desde luego, pero yo habría tardado más en localizarlo y tal vez no lo hubiese encontrado nunca." (234)

La lógica escapatoria del crimen organizado a fin de cuentas, donde, al igual que en la vida misma y como afirma Frankie, "los detalles cuentan." (I3) Detalles que irá analizando Frank Machiano/Frankie Machine, las dos caras de un sujeto que es a la vez un ejemplar ciudadano y un frío asesino a sueldo, durante la defensa de su vida, sabedor, por haber servido tanto al bando gubernamental como al de la mafia, de que sólo una acción extrema puede darle la vuelta al timón y cambiar la ruta en un giro de i8o grados. Decide entonces dar el giro extremo porque es él ahora la presa de ambos bandos. “¿Sabes por qué el gobierno quiere suspender el crimen organizado? [se pregunta] Porque le hace- 
mos competencia se responde]... La única diferencia entre ellos [el gobierno] y nosotros es que ellos son más organizados” (404) ¿Al César lo que es del César? Quede aquí el reconocimiento escrito por Winslow en el jalón final de esta dura narración.

\section{Muertey vida de Bobby $Z$}

Escrita por Don Winslow mucho antes, en I997, que El poder del perro, y por supuesto que Salvajes, aunque en español vio la luz pública entre ésta y aquella y de manera posterior a El Invierno de Frankie Machine -con un relevante prólogo de Rodrigo Fresán-, están ya en ella los detalles, los tics y los guiños de ojo que el autor desarrollará en las novelas posteriores enunciadas, así como el tono ácido y sarcástico bañado del buen humor e inherente a los creadores de la novela negra originaria creada por Carrol John Daily, Dashiell Hammett, Raymond Chandler, Horace Mc Coy, James M. Cain, Erle Stanley Gardner, David Goodis, Don Tracy, Jim Thompson y Ross Macdonald, y a sus subsecuentes cultivadores: de Donald Westlake, Jerome Charyn, Gerald Petievich, Robert B. Parker y Roger Simon, hasta James Ellroy, Barry Gifford, Elmore Leonard, George Pelecanos, Michael Conelly y John Conolly como las cimas vivientes del género.

Con Muerte y vida..., nuestro autor regresa a esa frontera, multicitada en estas líneas, como la zona que acrisola la guerra por el control del tráfico de drogas entre los cárteles mexicanos y estadounidenses, regada con la sangre de muchas víctimas inocentes generadas tanto por las fuerzas militares/policiales de ambos países como por los cárteles, también de ambos países -por las máquinas de guerra, pues.

Y en este contexto, Tim Kearney, un excombatiente en Irak de 27 años, un $<$ White Trash $>$ carne de presidio, un ladrón perdedor si los hay que cumple condena por un robo que irónicamente no cometió, es víctima de las circunstancias carcelarias y mata con una placa de carro afilada -hacerlas es el trabajo de Tim en la cárcel- a Stinkdog, conspicuo miembro de una pandilla de motociclistas, quien insistía para que Kearney ingresara a la Hermandad Aria y al no hacerlo lo amenaza con que ya verá, dice el racista, cómo le irá. “Tim contestó <<pues verás>>, y entonces fue cuando comprendió que lo mejor era afilar aquella placa de matrícula hasta dotarla de un filo quirúrgico" (Winslow, 2OIIb: I7). Y la usó en su defensa, frente a un tipo que le sacaba "unos 25 centímetros [de altura] y sesenta kilos [de peso].” (I8) Y firmó con ello su sentencia de muerte, porque los motociclistas pusieron precio a su cabeza.

Lo anterior puso feliz a Ted Gruzsa, agente de la DEA, porque resulta que Kearney es casi idéntico a un narcotraficante -guapo y surfero de Laguna Beach- de la costa californiana que ya está muerto, que era socio de Don Huertero, peligroso capo asentado en el norte de México y quien tiene secuestrado a Arthur Moreno, agente de la DEA y amigo de Gruzsa. Huertero no sabe que Bobby Z ha muerto, piensa que la DEA lo tiene preso de tiempo atrás, y secuestra a Moreno, cuya vida Gruzsa va a cambiar por la de Bobby Z interpretado por su casi doble: Tim Kearney -claro, si éste acepta hacerlo a cambio 
de suspenderle la cadena perpetua a que se ha hecho merecedor y dejarlo en libertad luego de cumplir el trabajo.

Claro que Tim y Gruzsa saben también que la tal libertad puede no llegar nunca para Tim Kearney/Bobby Z, aunque, piensa Tim, qué tal que sí, qué tal que logra embaucar a todos y se les desaparece; al final del día qué puede perder alguien que ha ingresado a la cárcel tres veces por robo en casas habitación, enviado a los marines por instrucciones del tribunal para terminar siendo condecorado por sus acciones en Arabia Saudita y ser echado de manera deshonrosa del cuerpo de élite militar, volver a la cárcel, salir de ésta y el día de su egreso ser recogido por su amigo Wayne LaPerriereu, quien en el camino detiene el automóvil en una gasolinera para, le dice a Tim, comprar cigarros. Lo malo para Tim es que Waine no compra tabaco, sino que asalta pistola en mano la tienda de la gasolinera mientras Kearney espera en el vehículo; y obvio: Tim va a la cárcel, porque Wayne hace un trato y dice que fue aquel el asaltante y dueño de la pistola. Con tales antecedentes, piensa Tim, nada puede perder aceptando la oferta de Gruza; seguro está de ello.

Tim acepta la propuesta de Ted Gruzsa, se prepara para ser de ahí en adelante Bobby Z y... el día del cambio se suceden una cadena de situaciones que hacen que todo salga mal y el ahora Bobby Z, que antes era Tim Kearney, huye por el desierto fronterizo siendo perseguido por la DEA, por el cartel de Don Huertero y por los motociclistas que quieren vengar la muerte de su hermano de sangre. En el periplo irá ajustando cuentas con su pasado, su presente y su dudoso futuro, en una acelerada persecución dosificada por Winslow en esta novela que, por doquiera que se le busque, deja entrever ya los recursos narrativos y la creación de atmósferas propias de su autor, así como la delimitación del paisaje fronterizo como el espacio idóneo para el crecimiento del narcotráfico como actividad y tópico en torno a los cuales el novelista edificará la hasta hoy triada más acabada al respecto: El poder del perro, Salvajes y Los reyes de lo cool. La historia de Bobby Z es, y así debe leerse, una primera aproximación, un apunte de la narconarrativa con vistas a la concreción de ésta como subgénero valedero para dar cuenta del presente violentamente compartido por México y Estados Unidos.

\section{Satori}

Winslow incursionó con ésta en los terrenos de la novela de espionaje en escenarios muy alejados de sus recurrentes y queridas playas californianas -Laguna Beach, en específico-, y de la frontera suroeste de su país con el nuestro, para dar cuenta de cómo durante el primer año de la segunda mitad del siglo XX el joven Nicholai Hel, experto en $<$ matar sin armas $>$ y preso en Japón durante 3 años por haber asesinado a su maestro y padrastro, es contactado por la CIA, para que a cambio de su libertad y de las ubicaciones de los estadounidenses que lo detuvieron, lo torturaron y lo desfiguraron, lleve a cabo el asesinato del delegado de la URSS, Yuri Voroshenin, en Pekín, trato que Hel acepta con 
la certeza de que las oportunidades de salir vivo de la acción son casi nulas. Así, luego de pasar por varias cirugías estéticas del rostro y de perfeccionar su francés, será enviado a China, con pasaporte de un francés que trafica con armas, para cumplir su cometido. Y en el viaje, Nicholai buscará lograr el satori, “el concepto budista zen del despertar súbito, la comprensión de la vida tal como es." (Winslow, 2OI2b: I5)

Basada en la novela Shibumi-estado del ser que se descubre y que se manifiesta en el acceso a la sencillez después del conocimiento-, de Trevanian, seudónimo del escritor Rodney William Whitaker, publicada en I972 -la primera edición en español por Plaza \& Janés data de 1979-, que fue éxito de ventas y que significó un giro en la manera de abordar la literatura de espionaje en tiempos de la guerra fría-donde los referentes $<$ bestselleros $>$ al respecto eran Ian Fleiming y su espía James Bond, así como John Le Carré y su personaje Smiley ${ }^{\mathrm{IO}}-$, la obra/remake de Winslow, en acuerdo con los herederos de Trevanian, respeta al personaje central y su historia de vida hasta salir de la cárcel y convertirse en un asesino a sueldo de la CIA, para de ahí insertarse en un puntual abordaje de la cambiante geopolítica de su tiempo, teniendo como escenarios China, Vietnam, la URSS, Japón..., y la incidencia en ella de los grupos de poder empresarial y político, en complicidad con el crimen organizado transnacional.

\section{Los reyes de lo cool}

Es ésta la obra con la cual, luego de haberse metido con la novela de Trevadian y de haberse dejado carcomer la pluma por la nostalgia de la costa oeste estadounidense bañada por el Océano Pacífico con El Club del amanecer, y su secuela La hora de los caballeros, Winslow volvió a lo que ha sido y es su apuesta literaria: la narrativa del narcotráfico como empresa económica y de sus circunstancias políticas y culturales. Es además esta novela la precuela de Salvajes que nos permite asistir no sólo al origen de las relaciones entre $\mathrm{O}$, Ben y Chon, sino al nacimiento del gran negocio de estos dos: al principio de los tiempos cuando los padres de los tres eran jóvenes y aquellos no eran ni siquiera un proyecto; al arranque y crecimiento del Cártel de Baja; a los entretelones de la incorporación de Elena al liderazgo del Cártel; a las concepciones/opiniones de Winslow respecto a su descarada filiación surfera y a la contracultura gringa; y a los orígenes del narcotráfi-

\footnotetext{
Io En la generalidad de la narrativa de espionaje -y en la de la novela policial también, valga decirlo- la calidad literaria brilla por su ausencia y su consumo es amplio-muestra de ello es toda la obra de Wiliam Le Queux y Phillips Oppeheim, durante las primeras décadas del siglo pasado-, aunque sus orígenes estén anclados en un solvente escritor como James Fennimore Copper en la tercera década del siglo XIX con su novela The Bravo (2006), que Rudyard Kipling haya publicado en el arranque del siglo XX Kim (1972) y que en dos aventuras <menores $>$ de Sherlock Holmes -Aventura del tratado naval (2003), y Aventura de los planos Bruce-Partington (2003)-éste haya ejercido como espía.

La primera obra adulta del género es El agente secreto (1983), de Joseph Conrad, a la que se agregarán las novelas de William Somerset Maugham y Eric Ambler, en el ámbito de la Primera Guerra Mundial. Y de lleno en tiempos de la guerra fría es Graham Greene quien mantiene la mayoría de edad del ¿subgénero?: escribe y publica su obra entre el arranque de la década de los cincuenta-El americano impasible (I955) - y fines de la década de los setenta-El factor humano (1987))-, en medio de las cuales están El cónsul honorario (1970), El agente confidencial (1986) y Nuestro hombre en La Habana (1995), por citar algunas.
} 
co hormiga, el de a poquito en poquito y sin grandes pretensiones de volverse millonario, entre Estados Unidos y México en los por aquel entonces nuevos tiempos que hoy son ya los mitificados viejos tiempos: los años sesenta del siglo pasado.

A fines de esa década donde parecería que todo pasó en Estados Unidos y el mundo: desde la emergencia de la lucha por los derechos civiles y en contra de la intervención gringa en Vietnam, a los movimientos juveniles y el asesinato político como algo inherente al american way of life, pasando por las drogas y el rock como sustentos culturales de los hijos de las flores, y el brusco despertar del sueño echando a rodar por el suelo la utopía pacifista y colectivista. A fines, pues, de la tal década mágica, es cuando se cimenta la relación transfronteriza más reciente y que incide hasta el presente, según Winslow, entre los narcotraficantes de allá y los de acá, al calor de los proyectos comunitarios del hipismo llegados a Laguna Beach como terreno natural luego de la huida/abandono de la esquina de High y Ashbury en San Francisco, California, y su encuentro con los surfistas: “¿La diferencia entre un surfista y un hippie?/ Una tabla. Básicamente son el mismo animal. El surfista fue el primer hippie; de hecho, fue el primer beatnik. Años antes que Jack [Kerouac] y Dean [Moriarty] salieran a la carretera en busca del dharma, el surfista recorría la Carretera Costera del Pacífico en busca de una nueva ola." (Winslow, 2OI2a: 7I)

Fue entonces cuando pasaron esos jóvenes de la idílica concepción de la producción de las drogas para autoconsumo, y de éstas como <las puertas de la percepción>, a la dura y sangrienta realidad de ellas como engranes de una empresa criminal que por encima de todo -de subalternos, familiares, socios y capos- coloca la permanencia del negocio y las ganancias. En la vida del narco el "dinero sólo es dinero... [y] continuamente se pierde algo. Lo mismo pasa con las personas: van a la cárcel, salen. Es el riesgo que corren. Un riesgo aplicable... por muy de la familia real que pueda ser. Sucede y la familia sigue adelante." (ІІ6) Y para seguir adelante tiene precisamente el dinero vuelto medio y fin que le permite comprar empresarios, autoridades civiles, militares y policiales en ambos países.

Cuestión elemental la anterior que advino cuando los tiempos estaban cambiando y los hippies aún no eran yuppies, pero sabían ya que sus proyectos comunitarios -literarios, gastronómicos, pedagógicos...- requerían de dinero, que "los surfistas [llevaban ya] años trayendo marihuana de sus expediciones por México y [que] su vehículo favorito para contrabandear [era] el Plymouth I954 familiar, porque todos sus paneles interiores [podían] ser desmontados, llenados con hierba y vueltos a montar.” (75) Y pasar, cuando los tiempos definitivamente cambiaron, de la hierba a la cocaína porque aquella, según Doc -personaje darwiniano síntesis del cambio de los tiempos de la narcopolítica a la necropolítica-, en ese momento era ya "pecata minuta. La coca [era] Wall Street. El rollo hippie [estaba] acabado. Paz, amor, métanselo por el culo. Jimi [Hendrix había] muerto. Janis [Joplin estaba] muerta... [y] todo [era] Simpatía por el Diablo.” (I22)

Era I976 entonces y los surfistas, esos pilgrins/slakers de la costa oeste que durante muchos años acarrearon hierba del sur al norte, empezaron a pasar coca, porque "el futuro [estaba] en el dinero y el dinero [estaba] en la coca. Los corredores de bolsa se 
meten coca [decía Doc]. Los productores de cine, los ejecutivos discográficos, los médicos, los abogados, los jefes indios... todos consumen coca, no hierba." (I22) Todo claro, pues: el mercado es el mercado y lo que se manifestó importante para "Los Que Mandan" no fue el negocio de la droga, sino el del territorio. Éstos, que vienen de aquella década dorada mitificada por muchos, averiguaron bien cómo funciona el tal negocio y pagan "a policías, jueces, abogados y matones, y cobran una tarifa a cambio de permitir que otros vendan drogas en su territorio. No tienen un puesto en el mercado, son los propietarios del mercado y se llevan un porcentaje de todos los puestos de los demás.” (I72)

Arranca así, a finales de la década de los sesentas, que terminaron muy entrados los setentas, el nuevo tiempo de las relaciones ilegales México-Estados Unidos, cuando, en palabras de un personaje central de Los reyes de lo cool, "vimos un sueño convertido en pesadilla vimos paz y amor convertidos en guerra y violencia interminable nuestro idealismo convertido en realismo nuestro realismo en cinismo nuestro cinismo en apatía nuestra apatía en egoísmo nuestro egoísmo en avaricia y después la avaricia fue buena y tuvimos..." (287) Sólo eso, que no es poco, por cierto.

Winslow aprovecha esta novela para hacer algunos ajustes con su obra de manera integral y con los tres personajes centrales debutantes en Salvajes, con sus respectivos árboles genealógicos y el actuar incidente de sus padres en las vidas del trío $\mathrm{O}$, Ben y Chon, del entrecruzamiento de éstas y de las de sus allegados por vía paterno/materna. Con la ventaja que le da la distancia temporal, el autor, como en Elpoder del perro, pasa del presente a finales de los sesentas y viceversa, para ir eslabonando y dándole razón de ser a las maneras de actuar de cada uno de los personajes, a los que bien pudiéramos dividir entre progenitores y descendientes, y hacerlos coincidir en tiempos y espacios actuales en una especie de vuelta de tuerca que resulta homenaje involuntario a Borges y su concepción del tiempo: el presente no existe como tal, siempre es ese fragmento de futuro que en un parpadeo ya es pasado, tiempo éste que, según Chon, es el único que "siempre nos acompaña. En nuestra historia. Nuestros cerebros, nuestra sangre." (332)

Y del pasado literario, de sus anteriores novelas y en lo que parece ser la apuesta por la construcción de una saga narrativa cuyos inicios están en esta especie de novela bisagra -obediente al mercado cinematográfico y literario que obliga a que las precuelas sean casi siempre creadas de manera posterior a las secuelas- y con sorprendente final, Winslow convoca en varias páginas de Los reyes de lo cool a personajes como Bobby Z, quien en r98I "es uno de los miembros más de la Asociación. Ultrarrelajado, ultracool, [y] mueve literalmente toneladas de Maui Wowi [variedad de marihuana hawaiana] entre la Costa Pacifista y la Costa Atlántica, prendiendo Times Square como nunca había prendido." (I89). Y personajes como Frankie Machine: "les presento a Frank Machiano. Va a mudarse a Laguna durante una temporada, así podrá controlar el terreno. Frank les tiende la mano a ambos. Un placer conocerles -dice. Voz muy suave. Competente. A John no se le escapa: Frank es asesino a sueldo." (205) Y como Dennis Cain, el agente de la DEA comprado por Ben, existente y actuante en Salvajes, lo que deja abierta la posibilidad, dada la manifiesta apuesta interdiscursiva del autor, de que en futuras obras aparezca de nueva 
cuenta Art Keller, personaje central de El poder del perro -a pregunta expresa de José A. Muñoz respecto a ello, Winslow respondió que quizás... que lo tiene en mente (2OIO $)^{\text {п. }}$.

\section{Alfinal}

La narconarrativa es un subgénero literario creciente dentro del amplio campo del realismo que acoge a la narrativa policial en general, y al género negro en particular, cuyos exponentes adultos habitan en, y han utilizado como escenario de los acontecimientos de que dan cuenta a, la frontera binacional México-Estados, convirtiéndola en lo que bien pudiéramos llamar una región literaria, entendida ésta como el espacio territorial imaginado -que no imaginario- donde la ficción realista se imbrica con la cotidianidad fronteriza realmente existente. Y dentro del subgénero de marras, el autor objeto de las líneas que están por terminar, se revela como el más consistente con por lo menos tres obras centrales y dos periféricas, de las cuales una de ellas es ya un clásico: Elpoder del perro.

La vorágine delictiva bajo la égida de una crueldad que asciende hasta alcanzar niveles enfermizos es un tópico nodal en las obras de Winslow que parecería, a simple vista, gratuita. Ante ello, el novelista define y asienta su punto de vista a propósito de la fuga de Joaquín "El Chapo" Guzmán-modelo para construir al personaje que transcurre, como ya se dijo, por las páginas de Elpoder del perro y The cartel- en lo que puede leerse como una declaración de principios ante las acusaciones de ser apólogo de la violencia y de su encantamiento con los narcos: "El hombre [Guzmán Loera] no es Robin Hood: es un asesino en masa." (2OI5b)

Asienta también, imbricada en la narrativa singular de cada obra, en la del conjunto de ellas y en cada uno de los diálogos interdiscursivos, una posición que riñe con el paradigma de la mayoría de los escritores -y guionistas de cine y televisión- estadounidenses que abordan los hechos criminales al sur del río Bravo: en Winslow, a pesar del tono en western noir que campea por sus novelas, no hay un protagonista remedo de John Wayne enfrentado a los corruptos, rupestres y torvos mexicanos o latinoamericanos en general, lo que no obsta para que algunos de sus personajes -Art Keller, Ben, Chon, por ejemplo- sean en el fondo, y a pesar de sus vicios privados, un puñado de justicieros a contracorriente de un mundo donde la corrupción, y el mal con atisbos bíblicos, es cuasi

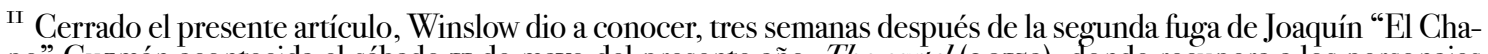
po" Guzmán acontecida el sábado II de mayo del presente año, The cartel (2OI5a), donde recupera a los personajes centrales de El poder del perro: Art Keller y Ádán Barrera. La historia transcurre entre 2004 y 2014 e incluye la primera fuga de Guzman en 2OOI. Sólo enunciamos aquí la novela por la falta de espacio para analizarla.

Publicada en español el I5 de octubre de este año por RBA, ganó ya el Premio de Novela Negra 20I5 de la citada editorial . (http://www.rbalibros.com/don-winslow-gana-el-premio-rba-de-novela-negra-2OI5-con-la-obra:-el-cartel_noticia-3658350-es.html) y Ridley Scott trabaja el guión para filmarla en 2016.

$\overline{\mathrm{E}}$ I 3 de mavo, a dos días de la fuga de Guzmán, Winslow (2OI5b) publicó en CNN un artículo acerca del escape, donde establece sus opiniones sobre el capo del cártel de Sinaloa -cuyo perfil utilizó para construir el de Adán Barrera-, su capacidad de corrupción y su fundamental papel en esa guerra estridente y sangrienta for export, que oculta las sucias relaciones entre los podres político empresariales y la délincuencia organizada a ambos lados de la frontera.
} 
la norma. Y tal es, parece decir Winslow, su virtud pública, lo que reafirma al través de su alter ego Art Keller en un diálogo de El cártel (2OI5c): "Si soy tan católico como usted dice... debería saber que creo que el mal es un absoluto, sin gradaciones." (Segunda parte, Cap. 5: 9I)

Y es ese resquicio, abierto, creemos, a propósito por el autor, el que le permite insertar con sustento y argumentos una visión integral del problema del narcotráfico mundial, y en específico del existente entre México y Estados Unidos, lleno de matices, de una gama de grises que abate los extremos del blanco y el negro. Lo que reafirma nuestro autor en una entrevista reciente: "la corrupción que en verdad está causando el problema no se encuentra en México sino en Estados Unidos. Una corrupción del tejido social que nos hace los consumidores de droga más importantes del mundo... [Y] como consumidores... financiamos la violencia en México, pero queremos mirar hacia otro lado en lugar de encarar los hechos." (Krauze, 20I5) Y El cártel es la muestra de que el políticamente correcto Winslow sacrifica quizás en aras de esta posición manifiesta en la entrevista, que inunda toda la novela y reivindica a los mexicanos "buenos", la posibilidad de haber alcanzado con su más reciente novela la cima en la que está El poder del perro; sin dejar de ser un portento de novela que se imbrica perfectamente con ésta para crear la panorámica mayor -constituida por cientos de close up, medium shots y planos americanos- del narcotráfico transfronterizo México-Estados Unidos de 1975 al 2OI4. Pero ésta historia no es objeto de estas líneas.

Elpoder del perro puede leerse como una tragedia shakespeareana, que recupera al genio inglés como soporte para utilizar un género literario -el policial negro que acoge a la narconarrativa y termina siendo novela histórica de lo inmediato- como el mejor dotado para dar cuenta de las circunstancias sociales que hacen hoy a la sociedad global y globalizada, donde los cables vinculatorios entre el campesino sembrador de amapola y mariguana con los grandes consorcios internacionales y los gobiernos de aquí y allá, pasan por la banca internacional y los mass media que blanquean el dinero del crimen, por ejemplo. Y el resto de la obra de Winslow, moralista y religioso al fin, como un retablo mayor de nuestros días más recientes, de los tiempos del Blade Runner ya entre nosotros; o mejor dicho: ya nosotros inmersos en ellos -en los tales tiempos, pues.

Al final Winslow, junto a algunos de los autores enunciados al inicio del presente artículo, reivindica a la frontera como espacio/escenario en el cual actúan personajes de ficción al lado de personajes reales ficcionalizados, posibilitando la emergencia de una región literaria en la que se gestan y manifiestan las contradicciones culturales, políticas, económicas y delincuenciales del lo que hemos dado en llamar ultracapitalismo, donde se degrada lo elementalmente humano que es la palabra como vehículo para dirimir cualquier contradicción o conflicto. Y para contar ese mundo se requiere un lenguaje grosero, vulgar, un slang sucio y políticamente incorrecto, aunque sea escrito por un autor políticamente correcto; capaz de decir, ante pregunta expresa de qué aconsejaría a México respecto a la violencia del narcotráfico: “ ¿Consejos para México? No tengo... ha recibido suficientes consejos de Estados Unidos. Simplemente le pediría disculpas.” (Krauze) 
Nada más, pero nada menos es la postura, el aporte y la apuesta de quien en el curso de los más recientes ocho años hizo acopio de una añeja tradición literaria con más de ochenta años de vida y puso ante los ojos de sus presuntos lectores una obra seria, donde el frenético y delirante vivir en la frontera entre nuestro país y el vecino del norte genera un estado de cosas plagado de violencia, que sólo mediante un estilo hiperrealista en amasiato con los más rojo de la nota roja, como el suyo y el de sus antecesores, puede intentar reconstruirse, porque como de siempre ha sido: la realidad supera a la ficción literaria y/o cinematográfica, aunque éstas sean mejores que la vida misma, más aún si el arte la media como acontece en la narrativa de Don Winslow.

Xalapa, I6-I8 de julio de 2oI3/Veracruz, puerto, 3 de agosto de 2013 ; poscriptum: octubre de 2015 


\section{Referencias}

- Aguilar Camín H. (2005). La conspiración de la fortuna. México: Planeta.

- Alarcón, O. (20io). Perra brava. México: Planeta.

- Almazán, A. (2009). Entre perros. México: Grijalbo/Mondadori.

- Almazán, A. (2012). Elmás buscado. México: Grijalbo.

- Astorga, L. (I995). Mitología del narcotraficante. México: Plaza y Valdés.

- Astorga, L. (1996). El siglo de las drogas. México: Espasa Calpe.

- Astorga, L. (1997). Los corridos de traficantes de drogas en México y Colombia, Revista Mexicana de Sociología. 58(4), 245-26r.

- Astorga, L. (2003). Drogas sin frontera: los expedientes de una guerra permanente. México: Grijalbo.

- Cacucci, P. (г993). San Isidro futbol. México: Universidad de Guadalajara.

- Carey, E. (2009). Selling is More of a Habit than Using. Narcotraficante Lola la Chata and Her Threat to Civilization, I930-I96o". Journal of Women’s History. 2I(2), 62-89.

- Cedillo, J. A. (20II). La Cosa Nostra en México (I938-1950). México: Grijalbo.

- Enciso, F. (20IO). Los fracasos del chantaje. Régimen de prohibición de drogas y narcotráfico. En Arturo Serrano y Mónica Alvarado. (Coords.). Los grandes problemas de México XV. Seguridad nacional y seguridad interior (6I-IO4). México: El Colegio de México.

- Conan Doyle, A. (2003). Todo Sherlock Holmes. Madrid: Cátedra.

- Connelly, M. (1993). El hielo negro. Barcelona: Roca.

- Conrad, J. (1983). El agente secreto. Barcelona: Seix Barral.

- Ellroy, J. (I993a). La dalia negra. Barcelona: Ediciones B.

- Ellroy, J. (1993b). Los Ángeles al desnudo. Barcelona: Ediciones B.

- Ellroy, J. (200Ia). América. Barcelona: Ediciones B.

- Elroy, J. (200Ib). Seis de los grandes. Barcelona: Ediciones B. 
- Elroy, J. (2005a). Elgran desierto. Barcelona: Ediciones B.

- Ellroy, J. (2005b). Jazz blanco. Barcelona: Ediciones B.

- Ellroy, J. (2OIO). Sangre vagabunda. Barcelona: Ediciones B.

- Ellroy, J. (2015). Perfidia. Barcelona: Random House/ Mondadori.

- Fennimore Copper, J. (1967). El bravo. Barcelona: De Gasso.

- Fresán, R. (199I). Historia argentina. Barcelona: Planeta.

- Fresán, R. (1995). Esperanto. Barcelona: Tusquets.

- Fresán, R. (200I). Mantra. Barcelona: Mondadori.

- Fresán, R. (2006). Jardines de Kesington. Barcelona: Mondadori.

- Fresán, R. (2009). Elfondo del cielo. Barcelona: Mondadori.

- García Niño, A. E. (2002). Ellroy, Gifford, Leonard: los forenses del sueño norteamericano. La Palabra y ElHombre, I23, I57-I7O.

- García Niño, A. E. (20I3), La narconarrativa: un subgénero literario fronterizo y binacional. Razón y Palabra, 4(84), s/p. Disponible en: http://www.razonypalabra.org.mx/N/ N84/V84/I4_Garcia_V84.pdf $>$.

- Gifford, B. (1992). Perdita Durango. Barcelona: Anagrama.

- Gifford, B. (1999). El asunto de Sinaloa. Barcelona: Destino.

- Greene, G. (1955). El americano impasible. Barcelona: Alianza.

- Greene, G. (1970). El cónsul honorario. Buenos Aires: Sur.

- Greene, G. (I986). El agente confidencial. Barcelona: Alianza.

- Greene, G. (1987). ElFactor humano. Santiago de Chile: Andrés Bello.

- Greene, G. (ı995). Nuestro hombre en La Habana. Barcelona: Alianza.

- Hammett, D. (1971). Cosecha roja. Barcelona: Bruguera.

- Hernández, A. (20Io). Los señores del narco. México: Grijalbo Mondadori. 
- Herrera, Y. (2004). Trabajos del reino. México: CONACULTA.

- Kipling, R. (1972). Kim. Madrid: Aguilar.

- Krauze, L. (20I5, septiembre). Entrevista a Don Winslow. "La manera de derrotar al narco es dejar de combatirlo", Letras Libres, 20I. Disponible en: http://www.letraslibres.com/ revista/entrevista/entrevista-don-winslow

- Mendoza, E. (1999). Un asesino solitario. México: Tusquets.

- Mendoza, E. (2002). El amante de Janis Joplin. México: Tusquets.

- Mendoza, E. (2004). Efecto tequila. México: Tusquets.

- Mendoza, E. (2008). Balas de plata. México: Tusquets.

- Mendoza, E. (20II). La prueba del ácido. México: Tusquets.

- Mendoza, E. (2012). Nombre de perro. México: Tusquets.

- Mbembe, A. (20II). Necropolítica. Barcelona: Melusina.

- Morán, D. (2OIO). Don Winslow. Realismo sucio (pero sucio de verdad). Rock de Lux. Obtenido el I7 de julio de 2013 desde http://www.rockdelux.com/radar/p/don-winslowrealismo-sucio-pero-sucio-de-verdad-.html.

- Nacaveva, A. (1967). Diario de un narcotraficante. México: Costa-Amic.

- Osorno, D. E. (2009). El cartel de Sinaloa. Una historia del uso político del narco. México: Grijalbo.

- Osorno, D. E. (20I2). La guerra de los zetas. Viaje por la frontera de la necropolítica. México: Grijalbo.

- Páez Varela, A. (2009). Corazón de Kaláshnikov. México: Planeta.

- Peña, H. (2009). Malasuerte en Tïuana. México: Grijalbo.

- Pérez-Reverte, A. (2002). La reina del sur. México: Alfaguara.

- Salerno, S. (2012). Don Winslow, Interviewed. Mulholland Books. Obtenido el I7 de julio de 2013 desde

<http://www.mulhollandbooks.com/2012/o7/o6/don-winslow-interviewed-by-shanesalerno/., 
- Trevanian (1979). Shibumi. Barcelona: Plaza \& Janés.

- Valenzuela, J. M. (2002). Jefe de jefes. Corridos y narcocultura en México. México: Plaza y Janés.

- Valle, E. (ı995). El segundo disparo. La narcodemocracia mexicana. México: Océano.

- Vidal, G. (เ975). Burr. Madrid: Grijalbo.

-Vidal, G. (1977). 1786. Madrid: Grijalbo.

- Vidal, G. (1994a). Washington, D.C. Barcelona: Ediciones B.

- Vidal, G. (I994b). Hoollywood. Barcelona: Ediciones B.

- Vidal, G. (2002). La edad de oro. Barcelona: Mondadori.

- Villalobos, J. P. (20I0). Fiesta en la madriguera. Barcelona: Anagrama.

- Weinman, S. (20I0). Live Chat with Don Winslow. Mulholland Books. Obtenido el I7 de Julio de 2013 desde http://www.mulhollandbooks.com/20I3/o8/og/live-chat-with-donwinslow/.

- Winslow, D. (2009a). Elpoder del perro. México: Grijalbo/Mondadori.

- Winslow, D. (20ogb). El club del amanecer. Barcelona: Roca.

- Winslow, D. (20п1a). El invierno de Frankie Machine. México: Martínez Roca.

- Winslow, D. (2OIIb). Muerte y vida de Bobby Z. Barcelona: Mondadori.

- Winslow, D. (20Irc). Salvajes. Barcelona: Martínez Roca.

- Winslow, D. (20I2a). Los reyes de lo cool. Barcelona: Mondadori.

- Winslow, D. (2012b). Satori. Barcelona: Roca Editorial.

- Winslow, D. (2OI2c). La hora de los caballeros. Barcelona: Martínez Roca.

- Winslow, D. (20I5a). The cartel. New York: Alfred A. Knopf.

- Winslow, D. (20I5b, I3 de Julio). El Chapo's Escape: No light at the end of his tunnel, CNN. Disponible en: http://edition.cnn.com/20I5/o7/I3/opinions/winslow-el-chapoescape/ 
- Winslow, D. (2015c). Elcártel. Barcelona: RBA. [versión ebook]

- Yépez, H. (2008). Alotro lado. México: Planeta. 